\title{
How Do Indoor Environments Affect Air Pollution Exposure?
}

\section{Goldstein, Allen H.; Nazaroff, William W.; Weschler, Charles J.; Williams, Jonathan}

\author{
Published in: \\ Environmental Science and Technology
}

Link to article, DOI:

10.1021/acs.est.0c05727

Publication date:

2020

Document Version

Peer reviewed version

Link back to DTU Orbit

Citation (APA):

Goldstein, A. H., Nazaroff, W. W., Weschler, C. J., \& Williams, J. (2020). How Do Indoor Environments Affect Air Pollution Exposure? Environmental Science and Technology, 55(1), 100-108.

https://doi.org/10.1021/acs.est.0c05727

\section{General rights}

Copyright and moral rights for the publications made accessible in the public portal are retained by the authors and/or other copyright owners and it is a condition of accessing publications that users recognise and abide by the legal requirements associated with these rights.

- Users may download and print one copy of any publication from the public portal for the purpose of private study or research.

- You may not further distribute the material or use it for any profit-making activity or commercial gain

- You may freely distribute the URL identifying the publication in the public portal

If you believe that this document breaches copyright please contact us providing details, and we will remove access to the work immediately and investigate your claim. 


\section{Lawrence Berkeley National Laboratory}

\section{Recent Work}

\section{Title}

How Do Indoor Environments Affect Air Pollution Exposure?

Permalink

https://escholarship.org/uc/item/7d59w47k

Journal

Environmental science \& technology, 55(1)

ISSN

0013-936X

\section{Authors}

Goldstein, Allen $\mathrm{H}$

Nazaroff, William W

Weschler, Charles J

et al.

Publication Date

2021

DOI

10.1021/acs.est.0c05727

Peer reviewed 


\section{How do indoor environments affect air pollution exposure?}

Allen H. Goldstein ${ }^{1,2, \star}$, William W Nazaroff ${ }^{2}$, Charles J. Weschler ${ }^{3,4}$, Jonathan Williams ${ }^{5}$

${ }^{1}$ Department of Environmental Science, Policy, and Management University of California, Berkeley, California 94720, United States

${ }^{2}$ Department of Civil and Environmental Engineering, University of California, Berkeley, California 94720, United States

${ }^{3}$ International Centre for Indoor Environment and Energy, Department of Civil Engineering, Technical University of Denmark, Lyngby 2800, Denmark

${ }^{4}$ Environmental and Occupational Health Sciences Institute, Rutgers University, Piscataway, New Jersey 08854, United States

${ }^{5}$ Max Planck Institute for Chemistry, 55128 Mainz, Germany

${ }^{*}$ Corresponding Author, email: ahg@berkeley.edu. 
1 Air pollution in urban areas is associated with adverse human health outcomes, including

2 cardiopulmonary disease and premature death. The relationships, determined largely through

3 epidemiological studies, drive regulatory policies for setting air pollution standards that are

4 designed to protect human health. Breathing predominantly occurs indoors and especially at

5 home. Therefore, indoor environments mediate the link between outdoor air pollution and human

6 exposure. In this perspective, we explore current understanding about the relationship between

7 air pollution, as characterized in monitoring networks, and inhalation exposures, which occur

8 largely indoors. Recognizing substantial and important gaps in knowledge, we suggest research

9 directions for advancing understanding at the nexus of outdoor air pollution, indoor

10 environments and exposure. We conclude with key points to consider when evaluating the

11 influence of indoor environments on air pollution exposure.

12

13 To illustrate the scale of concern, consider the most recent Global Burden of Disease study.

14 "Ambient particulate matter" (referring to $\mathrm{PM}_{2.5}$ ) ranked as the environmental factor with the

15 highest adverse health consequences, with 2.9 million attributable premature deaths and 83

16 million disability-adjusted life years (DALYs) lost per year globally in 2017. "Ambient ozone

17 pollution" contributed an additional 0.5 million premature deaths and 7.4 million DALYs per

18 year.

19

20 Buildings offer partial protection against pollutants of outdoor origin but enhance exposures to

21 particles and gases that are emitted or produced indoors. A survey of time apportionment for the

22 United States indicated that $87 \%$ of time on average is spent indoors (mostly in one's own

23 residence), more than $10 \times$ higher than the proportion of time spent outdoors. ${ }^{2}$ Consequently, 
24 most "ambient particulate matter" and "ambient ozone pollution" is breathed indoors, albeit at

25 concentration levels below outdoors. Furthermore, epidemiological studies of the link between

26 outdoor air pollution and health generally do not effectively address the often-substantial

27 exposure to air pollutants of indoor origin (e.g., emissions from cooking, cleaning, furnishings or

28 the inhabitants themselves). Indoor organic compounds are of particular note, since their

29 concentrations tend to be much larger than those outdoors and include species with known

30 adverse health effects (e.g., carcinogens, teratogens, endocrine disruptors), as well as persistent

31 organic pollutants and ozone reactive compounds.

32

33 How do buildings modulate exposures to outdoor particulate matter, outdoor ozone, and

34 hazardous organic air pollutants, and what additional exposures are attributable to indoor

35 sources? In other words, how different is the exposure that happens because we mainly breathe

36 indoor air, not outdoor air? We contribute toward answering these broad questions by posing

37 and commenting on three more focused questions.

38

39 Question 1. What chemical and physical transformations occur indoors that alter the form and composition of outdoor air pollution?

41 Airborne particles can span a diameter range covering about five orders of magnitude (0.001-100

$42 \mu \mathrm{m})$. As outdoor particles penetrate building envelopes and deposit on indoor surfaces, the

43 smallest (ultrafine) and largest (coarse) particles are removed to a greater extent than particles in

44 the intermediate size range (fine). ${ }^{3-6}$ Hence, as illustrated in Figure 1, indoor particles of outdoor

45 origin have a narrower distribution, centered about the most penetrating and persistent airborne

46 particles. When inhaled indoors, a larger proportion of these fine particles can travel deep into 
47 the respiratory tract. Being exposed to particles of outdoor origin while indoors shifts the pattern

48 of deposition in the respiratory tract owing to the effect of size-selective filtering of buildings.

50 The chemical composition of particles also changes with transport from outdoors to indoors

51 (Figure 1). Consider the partitioning of ammonia and nitric acid between the gas phase and

52 particle-phase ammonium nitrate. ${ }^{8}$ Transport to indoors is accompanied by several factors that

53 can each shift the gas-particle balance: change in temperature, loss of $\mathrm{HNO}_{3}$ to indoor surfaces,

54 and increased $\mathrm{NH}_{3}$ from indoor sources. ${ }^{9}$ Altering the abundance of $\mathrm{NH}_{4} \mathrm{NO}_{3}$ in particles can

55 shift particle $\mathrm{pH}$. Also, given that outdoor and indoor relative humidity routinely differ, ${ }^{10}$ it is

56 anticipated that the water content of outdoor airborne particles would change when transported

57 indoors, which can also modify particle $\mathrm{pH}$ and size distribution. A change in $\mathrm{pH}$ can

58 substantially influence the partitioning of acidic and basic gas-phase species to particulate

59 water. ${ }^{11,12}$

60

61 Another chemical transformation that occurs with outdoor-to-indoor transport is the shift in the

62 abundance and composition of semivolatile organic compounds (SVOCs) sorbed to airborne

63 particles. ${ }^{13-18}$ Certain SVOCs that are prominent in outdoor air, such as polycyclic aromatic

64 hydrocarbons (PAHs), can desorb from outdoor particles transported indoors. ${ }^{19}$ Other SVOCs,

65 which are prominent indoors, can sorb to particles that are transported into buildings. Common

66 examples of abundant indoor SVOCs are phthalate ester plasticizers, brominated flame

67 retardants, and perfluorinated surfactants. ${ }^{20}$ Under conditions with minimal indoor particle

68 emissions, particles of outdoor origin have been shown to quickly sorb indoor SVOCs, ${ }^{16}$

69 resulting in larger mass fractions of particulate SVOCs indoors than outdoors. ${ }^{17}$ 
71 In summary, several features of indoor environments result in physical and chemical

72 transformations such that indoor particles of outdoor origin differ meaningfully in size

73 distribution and chemical composition from their outdoor precursors. Such changes might well

74 influence the health consequences associated with inhaling them.

75

76 Ozone reacts with surfaces it encounters as it is transported indoors and, subsequently, with

77 compounds on exposed indoor surfaces. Ozone also reacts, to a lesser extent, in indoor air. The

78 aggregate effect is that indoor ozone concentrations are commonly lower than those found

79 outdoors. The reactions that consume ozone generate both gaseous and condensed-phase

80 products. The indoor concentration of gas-phase reaction products can be larger than the indoor

81 concentration of ozone itself. ${ }^{21-23}$ Indoors, humans inhale both ozone of outdoor origin and

82 indoor-generated oxidation products derived from outdoor ozone. Given the large fraction of

83 time spent indoors, the amount of ozone inhaled indoors is approximately equal to ozone inhaled

84 outdoors, and inhalation of products derived from outdoor ozone is comparable to or larger than

85 the total inhalation of ozone itself. ${ }^{21-23}$ Notably, there is a strong link between indoor moisture

86 and the products of indoor ozone chemistry. As the indoor water vapor concentration increases,

87 ozone reactions with skin oil constituents have been shown to yield fewer secondary ozonides,

88 more carbonyls and an overall increase in gas-phase products. ${ }^{24,25}$ Many studies address ozone's

89 toxicity. However, the toxicity of many of its oxidation products is poorly characterized. This is

90 especially true for stabilized Criegee intermediates, secondary ozonides, epoxides, and

91 hydroperoxides. When considering ozone pollution and its health consequences, most studies 
92 overlook the coincident indoor exposure to ozone-derived products and their potential

93 contribution to the mortality and morbidity attributed to outdoor ozone.

94

95 Organic air pollutants that are almost exclusively gaseous outdoors partition between the gas

96 phase and indoor surfaces, ${ }^{26}$ reflecting surface-to-volume ratios that are markedly larger indoors

97 than outdoors. ${ }^{27}$ Sorption serves to reduce indoor exposure to outdoor organic pollutants during

98 the peak of an outdoor episodic emission but extends the overall time of exposure to pollutants.

99 The indoor mixture of organic air pollutants results from a combination of indoor and outdoor

100 sources depending on ventilation and infiltration conditions. Importantly, there are many strong

101 indoor sources of organic pollutants (e.g., buildings and their contents, cooking, cleaning,

102 occupant metabolic emissions, personal care products, skin oil oxidation, consumer products,

103 indoor combustion), resulting in indoor concentrations that are commonly an order of magnitude

104 larger and chemically distinct from those outdoors (e.g., compounds emitted from vegetation, 105 motor vehicles, solid fuel combustion, industry or fires). Coupled with the large fraction of time 106 people spend indoors, inhalation of organic pollutants can be orders of magnitude larger indoors 107 than outdoors and is generally dominated by indoor sources.

108

109 Question 2: How do building and human factors influence the nature and extent of 110 modulation of air pollution exposures?

111 The infiltration factor quantifies the extent to which buildings are protective against airborne 112 particles of outdoor origin. This term represents the indoor-to-outdoor particle concentration 113 ratio when all indoor particles originate outdoors. The infiltration factor is controlled by loss 114 processes that occur passively (deposition to surfaces) or by design (filtration in mechanical 
115 ventilation systems). A central-tendency estimate for the infiltration factor of $\mathrm{PM}_{2.5}$ is 0.5 and 116 studies report average values ranging from 0.3 to $0.8 .^{28}$ Buildings are much more effective at

117 limiting the outdoor-to-indoor transport of ultrafine and coarse-mode particles. ${ }^{29}$ Overall, in

118 central tendency, buildings provide substantial but imperfect protection from outdoor particles.

119 Furthermore, there is considerable variability in infiltration factors across the building stock.

120

121 Buildings are also protective against outdoor ozone exposure, largely because ozone reacts

122 chemically with indoor surface materials. A compilation of empirical results studying the

123 indoor/outdoor ratio for ozone in buildings without known indoor sources suggests a central

124 tendency of about 0.25 with variation commonly spanning the range $0.1-0.6 .^{23,30}$

125

126 Important consequences ensue from the partial and variable protection provided by buildings

127 against outdoor air pollution. In epidemiological studies, actual inhalation intake of outdoor air 128 pollutants such as fine particles and ozone is lower than monitoring networks would indicate.

129 Furthermore, exposures are variable across populations owing to differences in the factors that 130 influence the degree of protection provided by buildings. For example, because of climate131 associated variation in building design and operation, systematic spatial differences occur in the 132 indoor-outdoor relationship of outdoor pollutants. Accounting for variability from location to 133 location in air change rates, augmented by the fraction of time spent indoors, has partially 134 explained observed regional differences in associated health effects for ozone, ${ }^{22} \mathrm{PM}_{2.5},{ }^{31}$ and $135 \mathrm{PM}_{10}{ }^{32}$ Furthermore, there can be systematic variation in infiltration factors in the buildings 136 occupied by subpopulations, which may correlate with factors such as age, socioeconomic 137 conditions, and health status. 
139 Prominent epidemiologic and risk assessment studies commonly overlook the roles of buildings

140 attenuating and modulating inhalation exposures of occupants. For example, Brauer et al. ${ }^{33}$ did

141 not account for attenuation in exposures associated with buildings in their extensive effort to

142 estimate population exposures to outdoor $\mathrm{PM}_{2.5}$ and ozone for the Global Burden of Disease

1432013 study. Burnett et al. ${ }^{34}$ constructed an integrated exposure-response model for $\mathrm{PM}_{2.5}$,

144 synthesizing exposure and disease outcome information for "ambient air pollution, secondhand

145 tobacco smoke, household solid cooking fuel, and active smoking." That effort neglected

146 building-associated attenuation of outdoor air pollution exposure, therefore biasing the outcome.

147 An assessment of how global mortality might shift with changes in outdoor $\mathrm{PM}_{2.5}$ concentrations

148 likewise neglects the role of buildings as attenuators and modulators of exposure. ${ }^{35}$ Efforts to

149 incorporate the effects of buildings in health risk assessments for outdoor air pollution have been

150 reported, ${ }^{36,37}$ but these issues have not yet taken root to influence major epidemiological studies.

151

152 The uneven ability to characterize exposures well may influence the outcomes of air-pollution

153 epidemiology studies. For particles, the connection between $\mathrm{PM}_{2.5}$ and health effects understood

154 through epidemiological studies is superior to the knowledge for health effects of ultrafine and

155 coarse-mode particles. Part of the reason is that smoother spatial gradients occur outdoors for

$156 \mathrm{PM}_{2.5}$, which is largely secondary with a longer atmospheric persistence time than coarse-mode

157 or ultrafine particles. Consequently, monitoring networks provide a more accurate representation

158 of the spatial and temporal distribution of outdoor $\mathrm{PM}_{2.5}$ than would be possible for other particle

159 size modes. Given that buildings generally provide a high degree of protection against ultrafine

160 and coarse particles, combined with significant indoor sources of these modes, we are currently 
161 in a state of near blindness about actual inhalation exposure to ultrafine and coarse particles. The

162 same level of poor understanding applies to many of the pollutants for which indoor emissions

163 are the dominant contributors to exposure, such as most organic pollutants.

164

165 Question 3: Which air pollutants have indoor sources leading to generally higher

166 concentrations and exposures indoors than outdoors, and which of these may be

167 particularly important for health?

168 The mix of indoor, outdoor, primary and secondary chemicals is modulated through buildings

169 and the ways in which we construct and operate them. Since people spend $\sim 70 \%$ of their time at

170 home, we focus here on residences. Every home may have a unique combination of smells and

171 activities, but in fact they have much in common that is generalizable. At their most basic,

172 houses are boxes, constructed out of a relatively small range of materials, that exchange mass

173 and energy with their surroundings. Buildings are operated to meet the requirements for thermal

174 comfort and respiratory metabolism of their occupants. With global supply chains, there is more

175 commonality in building materials and operations than might have been the case historically.

176 Standardized building materials and furniture are now available worldwide from rapidly growing

177 international vendors. Ventilation, filtration, and thermal comfort provisions are achieved

178 through a few core technologies. Thus, whereas the nexus between outdoor environments, indoor

179 air quality, and indoor exposure is richly complex, there are a core set of reasonably well-defined

180 scientific principles and engineering tools with which to make generalizable progress.

181

182 To elaborate, notwithstanding the wide variety of buildings, sources, human occupancy, and

183 activities, there is surprising commonality in indoor composition of organic chemicals in 
184 residences. ${ }^{38-41}$ Ample sources of VOCs and SVOCs cause their abundance in indoor air to be 185 greatly enhanced above what is present in outdoor air for a broad suite of chemical classes.

186 Typical sources include plastics and polymers (emitting plasticizers, flame retardants,

187 antioxidants), pressed wood products (formaldehyde, organic acids), synthetic carpets (flame

188 retardants, anti-stain agents, antioxidants), cleaning products, fragrances (terpenoids readily

189 oxidized to undesirable products), appliances (flame retardants, particles, thermal greases, oils),

190 other building materials, and common consumer products. ${ }^{42-48}$ Remarkably, it is now becoming

191 recognized that the ventilation of these chemicals from indoor environments can make

192 significant contributions to outdoor air pollutant loadings in cities. ${ }^{49,50}$

193

194 Human beings are themselves potent mobile sources of volatile organic compounds (VOCs),

195 inorganic compounds and particles in indoor environments. ${ }^{50-53}$ We shed skin flakes and

196 microbes and we transfer skin oils to indoor surfaces. Several hundred bioeffluent VOCs are

197 known to be emitted via breath and skin. ${ }^{54}$ Emissions of VOCs from personal care products are

198 ubiquitous. In the presence of oxidants such as ozone, a multitude of chemical byproducts can be

199 formed, ${ }^{24,55}$ some of which (e.g., 4-OPA) are known irritants. ${ }^{56}$ As well as innately emitting into

200 their immediate environment, various human activities indoors, such as cooking, cleaning,

201 smoking, have been shown to introduce large quantities of gases and particles to indoor air.

202 Indoor sources are uncommon (although not rare) for ozone and include devices that produce a

203 corona discharge (e.g., electrostatic precipitators, photocopiers, and "ozone generators"). ${ }^{57}$ For

204 particles, indoor sources are common and contribute substantially to exposures both acute and

205 chronic, with differing impacts on immune system responses. ${ }^{58-61}$ Among the prominent

206 important indoor sources of particles are smoking ${ }^{62}$ and cooking. ${ }^{63}$ Candle use has been 
207 identified as an important source of indoor ultrafine particles. ${ }^{64}$ Resuspension ${ }^{65}$ and shedding ${ }^{66}$ 208 contribute to airborne coarse-mode particles indoors. While $\mathrm{PM}_{2.5}$ abundance inside residences is 209 often lower than outdoors, during specific types of events (e.g., smoking, cooking, candle use), 210 and via resuspension, much higher concentrations can occur indoors than outdoors.

211 Secondary sources of air pollutants can also be important indoors. Specifically, oxidation 212 products from outdoor ozone infiltrating and reacting with alkenes on exposed indoor surfaces, ${ }^{67}$

213 in skin oil, and in the gas-phase are ubiquitous. Reactions with terpenes and terpene alcohols 214 used as scenting agents in a variety of indoor cleaners and "air fresheners" are common. ${ }^{48}$

215 Additional reactions in the gas phase and on surfaces can occur sporadically because of occupant 216 activities. ${ }^{68,69}$ Noteworthy examples include addition of oxidants such as hypochlorite in bleach 217 and related products (chlorine chemistry), changing surface $\mathrm{pH}$ via cleaning with ammonia or 218 vinegar, and changing surface moisture through intentional humidification. Oxidants such as $\mathrm{OH}$ 219 and $\mathrm{NO}_{3}$ are assumed to be at generally low concentrations indoors making them typically less 220 important as sources of secondary organics than is the case outdoors during daytime. ${ }^{70,71}$

221 Kirk Smith aptly advised, that to advance scientific understanding and improve the human 222 condition, we need to "follow the risk" ${ }^{72}$ Research is needed to determine which of the 223 numerous organic chemicals or chemical classes found indoors may be particularly important as 224 health risks. Among known candidates, $\mathrm{PM}_{2.5}$, acrolein, and formaldehyde have been identified 225 as accounting for the vast majority of DALY losses caused by indoor air pollutants, with impacts 226 equal to or larger than those estimated for radon and secondhand tobacco smoke. ${ }^{73}$ In current 227 morbidity and mortality studies, $\mathrm{PM}_{2.5}$ is assumed to be equitoxic, despite known dependencies 228 on chemical composition. ${ }^{74}$ How indoor emissions and processes affect $\mathrm{PM}_{2.5}$ toxicity is a key 
229 question for future research. Indoor sources of formaldehyde, as well as the health impacts of

230 this smallest aldehyde, have been extensively studied. ${ }^{75}$ Carcinogenic chemicals (e.g., benzene,

231 benzo[a]pyrene (BaP), radon, nitrosamines) are another category of concern for indoor air

232 exposure. ${ }^{76}$ Although PAHs may be elevated in outdoor particles, indoor combustion is also a

233 source, including of the carcinogenic benzo(a)pyrene. Nitrous acid has been shown to react with

234 nicotine and other third-hand smoke components to generate carcinogenic nitrosamines. ${ }^{77}$

235 When chemicals enter the human body, some interact with our regulatory system disrupting the

236 autoregulatory processes that rely on chemical signaling. ${ }^{78,79}$ More than 100,000 new chemicals

237 have been introduced as constituents of commercial products in recent decades, including many

238 used deliberately or inadvertently in indoor environments. ${ }^{80,81}$ An emerging body of evidence

239 suggests some widely used commercial chemicals are endocrine disruptors. ${ }^{82,83}$ Some chemicals

240 of concern as endocrine disruptors have substantially higher concentrations indoors compared to

241 outdoors. Phthalates are a prime example. ${ }^{17}$ Human exposures to semivolatile organic

242 compounds are dominated by indoor environments both through inhalation and dermal

243 uptake. ${ }^{84,85}$ Diseases believed to be influenced by environmental exposures to endocrine

244 disrupting chemicals have increased over time, including asthma, allergy, Alzheimer's disease,

245 psychogenic processes, eating disorders, chronic obesity, and possibly autism. ${ }^{86-88}$ While indoor 246 exposure to many SVOCs that are suspected endocrine disruptors has increased, the clinical

247 relevance of these indoor exposures and the molecular basis for increased adverse health risks

248 remain subjects for future multidisciplinary investigations. 

and exposure.

251 Human exposure to harmful air pollutants results from a combination of outdoor and indoor 252 sources. These are difficult to delineate since exposure occurs mostly indoors and especially 253 within the home. Although outdoor measurements of ozone and $\mathrm{PM}_{2.5}$ are used to link air 254 pollution to health effects, they are proxies for more complex chemical and physical processes 255 that act at the intersection of outdoor air pollution, indoor environments and exposure. 256 Understanding these processes should be a research focus to ensure future wellbeing. 257

258 Global trends show that the world's population is migrating from the countryside to cities. By 2592050 , some $70 \%$ of humanity will live in urban areas. ${ }^{89,90}$ This shift is occurring despite the per capita mortality rate attributable to air pollution being approximately $50 \%$ higher in urban than in

261 rural areas. ${ }^{91}$ The resulting increased demand for urban housing and potential for rising levels of 262 outdoor pollutants including ozone ${ }^{92}$ will likely lead to smaller living spaces and tighter 263 structures in which indoor sources and chemical processing increase in importance. Lower 264 indoor-outdoor air-change rates are also anticipated as housing becomes more energy efficient 265 and heat exchange restricted. With continued warming of urban atmospheres, ${ }^{93}$ air conditioning 266 will become more prevalent. In some of the world's hottest regions, such as the Eastern 267 Mediterranean and Middle East, home to over 400 million people, most already reside in urban 268 areas where life without active cooling is barely tenable. ${ }^{94}$ Therefore, it seems likely that future 269 homes will tend to be increasingly isolated from the outside. Living and working conditions 270 described by temperature, humidity, and chemical exposure will be more directly influenced by 271 buildings and inhabitants. While effectively designed and operated mechanical ventilation 
272 systems coupled with air-cleaning technologies can attenuate their impact, building occupants

273 will remain susceptible to exposures that originate from pollutants emitted indoors.

275 Improvements in outdoor and indoor air quality can improve human health. Landrigan et al. ${ }^{95}$

276 estimated that in 2015, polluted air was responsible for 6.4 million deaths and economic losses of

277 US\$21 billion worldwide. Lowering urban and regional air pollution requires the concerted

278 action of a population that possesses considerable societal inertia. The continued use of the

279 outside atmosphere as a repository for pollutant emissions is therefore a lamentable but also 280 likely future condition as a modern-day tragedy of the commons. ${ }^{96}$ A further complication for air

281 pollution control strategies is that the sources of outdoor $\mathrm{PM}_{2.5}$, which is our clearest link to 282 premature mortality, vary considerably with location. In Asia, where most premature deaths 283 attributed to air pollution occur, residential energy use for heating and cooking is a substantial 284 source of emissions, while in Europe, parts of the USA, Russia and East Asia agriculture plays 285 an important role, and in large sections of the USA traffic and power generation are dominant 286 sources. $^{91}$

People have more direct control over their exposure indoors than outdoors, and this potential for 289 control is especially germane in parts of the world that have serious outdoor air pollution issues, 290 such as India and China. Opportunities to intervene exist, modifying building systems to 291 deliberately reduce air pollution exposure and thereby improve occupant health. Activated 292 carbon filters have been demonstrated to be effective in controlling ozone. ${ }^{97}$ High-quality 293 particle filters can substantially reduce indoor particle levels ${ }^{98}$ and can be cost effective. ${ }^{99-101}$ 294 Intervention studies have documented improved outcomes for biomarkers of health through 
295 building-level air-pollution mitigation, ${ }^{102,103}$ although overall health improvements have been 296 judged to be relatively modest compared to the substantial reduction in indoor PM using

297 filtration. ${ }^{104}$ Nonetheless, building-level interventions can be applied with local control on a 298 much faster time scale than interventions for improving outdoor air pollution.

300 As isolation of the home environment from outside air is common and likely increasing, 301 architectural innovations have potential to play an important role in mediating chemical exposure 302 between our lungs and the environment. Cleansing facilities and practices (e.g., doormats, shoe 303 brushes, shoe removal) at the home entrance to limit importation of particles and chemicals into 304 the home, efficient range hoods, transitioning from gas to electric stoves, use of lower emitting 305 materials, frequent cleaning of clothing as protection from indoor exposure, and increased air 306 cleaning via filtration of recirculated air in whole-house HVAC systems or portable units in 307 selected rooms ${ }^{104}$ are all possible adaptions. Such protective strategies can be adopted by 308 individuals, even while community-wide emission reductions of outdoor pollutants are pursued.

\section{Synthesis}

311 We highlight key points to consider when evaluating the influence of indoor environments on air 312 pollution exposure:

313 - Most of our inhalation of outdoor PM occurs indoors, and when indoors we are exposed 314 preferentially to outdoor fine PM, the size range that is most efficient at penetrating deeply 315 into our lungs.

316 - Buildings most effectively attenuate the ingress of outdoor ultrafine- and coarse-mode 317 particles. Indoor sources can make large contributions to inhalation exposures of the smallest 
and largest particles. Epidemiological studies that rely on outdoor air concentrations have elicited consistent associations (but not demonstrated causation) between $\mathrm{PM}_{2.5}$ and adverse health outcomes. Studies that rely on outdoor concentrations as proxy measures of exposure are likely to be less successful in assessing health consequences of exposure to ultrafine and

$322 \quad$ coarse mode particles.

323 - Inhalation of outdoor ozone occurs almost equally indoors and outdoors. Indoor inhalation of 324 the products of indoor reactive chemistry initiated by ozone originating outdoors can be 325 larger than the aggregate inhalation of ozone itself.

- The concentration of gas-phase organic compounds is commonly an order of magnitude

327 larger indoors than outdoors. In part, this reflects contributions from scenting agents, cyclic 328 and linear siloxanes, plasticizers, flame retardants, perfluorinated surfactants, pesticides and 329 cooking emissions. Given the large fraction of time spent indoors, cumulative inhalation of 330 gas-phase organics occurs at approximately two orders of magnitude higher daily rate from 331 breathing indoor air rather than outdoor air.

332 - Outdoor $\mathrm{PM}_{2.5}$ transported indoors sorbs semivolatile organic compounds released from 333 indoor sources. When inhaled, these particles carry the sorbed organics deeper into the 334 respiratory tract than would be the case for the gas-phase counterparts.

336 Implications from our perspective include these three points:

337 - Science might be missing some of the important health consequences associated with air 338 pollution by failing to properly understand how buildings modulate air pollution exposures. 339 - The apparently equitoxic nature of $\mathrm{PM}_{2.5}$ might reflect inadequate understanding of inhaled 340 particle composition, in contrast to particle composition in outdoor air. Future studies that 
341 aim to elucidate the most health-harmful components of inhaled $\mathrm{PM}_{2.5}$ should take account of 342 indoor modulation and modification of $\mathrm{PM}_{2.5}$ constituents.

343 - Indoor environments materially alter the link between outdoor air pollution and human

344 exposure. Core elements of understanding were identified several decades ago, ${ }^{105}$ but the 345 lessons have not been widely learned. In failing to account for how indoor environments 346 affect air pollution exposure, epidemiologists are overlooking critical elements needed to 347 make the important transition from association to causation.

348

349

\section{References}

1. Stanaway, J. D.; Afshin, A.; Gakidou, E.; et al. Global, regional, and national comparative 351 risk assessment of 84 behavioural, environmental and occupational, and metabolic risks or 352 clusters of risks for 195 countries and territories, 1990-2017: a systematic analysis for the 353 Global Burden of Diseases Study 2017. Lancet. 2018, 392, 1923-1994.

354 2. Klepeis, N. E.; Nelson, W. C.; Ott, W. R.; Robinson, J. P.; Tsang, A. M.; Switzer, P.; Behar, 355 J. V.; Hern, S. C.; Engelmann, W. H. The National Human Activity Pattern Survey 356 (NHAPS): a resource for assessing exposure to environmental pollutants. Journal of Exposure Analysis and Environmental Epidemiology. 2001, 11, 231-252.

358 3. Long, C. M.; Suh, H. H.; Catalano, P. J.; Koutrakis, P. Using Time- and Size-Resolved 359 Particulate Data to Quantify Indoor Penetration and Deposition Behavior. Environmental $360 \quad$ Science \& Technology. 2001, 35, 2089-2099.

4. Riley, W. J.; McKone, T. E.; Lai, A. C. K.; Nazaroff, W. W. Indoor Particulate Matter of 
5. Thatcher, T. L.; Lunden, M. M.; Revzan, K. L.; Sextro, R. G.; Brown, N. J. A Concentration Rebound Method for Measuring Particle Penetration and Deposition in the Indoor Environment. Aerosol Science \& Technology. 2003, 37, 847-864.

6. Rim, D.; Wallace, L.; Persily, A. Infiltration of Outdoor Ultrafine Particles into a Test House. Environmental Science \& Technology. 2010, 44, 5908-5913.

7. Zhang, Q.; Jimenez, J. L.; Canagaratna, M. R.; Allan, J. D.; Coe, H.; Ulbrich, I.; Alfarra, M. R.; Takami, A.; Middlebrook, A. M.; Sun, Y. L.; Dzepina, K.; Dunlea, E.; Docherty, K.; DeCarlo, P. F.; Salcedo, D.; Onasch, T.; Jayne, J. T.; Miyoshi, T.; Shimono, A.; Hatakeyama, S.; Takegawa, N.; Kondo, Y.; Schneider, J.; Drewnick, F.; Borrmann, S.; Weimer, S.; Demerjian, K.; Williams, P.; Bower, K.; Bahreini, R.; Cottrell, L.; Griffin, R. J.; Rautiainen, J.; Sun, J. Y.; Zhang, Y. M.; Worsnop, D. R. Ubiquity and dominance of oxygenated species in organic aerosols in anthropogenically-influenced Northern Hemisphere midlatitudes. Geophysical Research Letters. 2007, 34, L13801.

8. Lunden, M. M.; Revzan, K. L.; Fischer, M. L.; Thatcher, T. L.; Littlejohn, D.; Hering, S. V.; Brown, N. J. The transformation of outdoor ammonium nitrate aerosols in the indoor environment. Atmospheric Environment. 2003, 37, 5633-5644.

9. Nazaroff, W. W.; Weschler, C. J. Indoor acids and bases. Indoor Air. 2020, 30, 559-644.

10. Nguyen, J. L.; Schwartz, J.; Dockery, D. W. The relationship between indoor and outdoor temperature, apparent temperature, relative humidity, and absolute humidity. Indoor Air. 2014, 24, 103-112.

11. Collins, D. B.; Wang, C.; Abbatt, J. P. D. Selective Uptake of Third-Hand Tobacco Smoke Components to Inorganic and Organic Aerosol Particles. Environmental Science \& Technology. 2018, 52, 13195-13201. 
12. DeCarlo, P. F.; Avery, A. M.; Waring, M. S. Thirdhand smoke uptake to aerosol particles in the indoor environment. Science Advances. 2018, 4, eaap8368.

13. Avery, A. M.; Waring, M. S.; DeCarlo, P. F. Seasonal variation in aerosol composition and concentration upon transport from the outdoor to indoor environment. Environmental Science: Processes \& Impacts. 2019, 21, 528-547.

14. Hodas, N.; Turpin, B. J. Shifts in the Gas-Particle Partitioning of Ambient Organics with Transport into the Indoor Environment. Aerosol Science and Technology. 2014, 48, 271-281.

15. Johnson, A. M.; Waring, M. S.; DeCarlo, P. F. Real-time transformation of outdoor aerosol components upon transport indoors measured with aerosol mass spectrometry. Indoor Air. 2017, 27, 230-240.

16. Lunderberg, D. M.; Kristensen, K.; Liu, Y.; Misztal, P. K.; Tian, Y.; Arata, C.; Wernis, R.; Kreisberg, N.; Nazaroff, W. W.; Goldstein, A. H. Characterizing Airborne Phthalate Concentrations and Dynamics in a Normally Occupied Residence. Environmental Science \& Technology. 2019, 53, 7337-7346.

17. Lunderberg, D. M.; Kristensen, K.; Tian, Y.; Arata, C.; Misztal, P. K.; Liu, Y.; Kreisberg, N.; Katz, E. F.; DeCarlo, P. F.; Patel, S.; Vance, M. E.; Nazaroff, W. W.; Goldstein, A. H. Surface Emissions Modulate Indoor SVOC Concentrations through Volatility-Dependent Partitioning. Environmental Science \& Technology. 2020, 54, 6751-6760.

18. Meng, Q. Y.; Turpin, B. J.; Lee, J. H.; Polidori, A.; Weisel, C. P.; Morandi, M.; Colome, S.; Zhang, J.; Stock, T.; Winer, A. How Does Infiltration Behavior Modify the Composition of Ambient $\mathrm{PM}_{2.5}$ in Indoor Spaces? An Analysis of RIOPA Data. Environmental Science \& Technology. 2007, 41, 7315-7321. 
19. Naumova, Y. Y.; Offenberg, J. H.; Eisenreich, S. J.; Meng, Q.; Polidori, A.; Turpin, B. J.; Weisel, C. P.; Morandi, M. T.; Colome, S. D.; Stock, T. H.; Winer, A. M.; Alimokhtari, S.; Kwon, J.; Maberti, S.; Shendell, D.; Jones, J.; Farrar, C. Gas/particle distribution of polycyclic aromatic hydrocarbons in coupled outdoor/indoor atmospheres. Atmospheric Environment. 2003, 37, 703-719.

20. Lucattini, L.; Poma, G.; Covaci, A.; de Boer, J.; Lamoree, M. H.; Leonards P. E. G. A review of semi-volatile organic compounds (SVOCs) in the indoor environment: occurrence in consumer products, indoor air and dust. Chemosphere. 2018, 201, 466-482.

21. Weschler, C. J. Ozone's Impact on Public Health: Contributions from Indoor Exposures to Ozone and Products of Ozone-Initiated Chemistry. Environmental Health Perspectives. 2006, 114, 1489-1496.

22. Chen, C.; Zhao, B.; Weschler, C. J. Indoor Exposure to "Outdoor PM10" - Assessing Its Influence on the Relationship Between $\mathrm{PM}_{10}$ and Short-term Mortality in U.S. Cities. Epidemiology. 2012, 23, 870-878.

23. Yao, M.; Weschler, C. J.; Zhao, B.; Zhang, L.; Ma, R. Breathing-rate adjusted population exposure to ozone and its oxidation products in 333 cities in China. Environment International. 2020, 138, 105617.

24. Arata, C.; Heine, N.; Wang, N.; Misztal, P. K.; Wargocki, P.; Bekö, G.; Williams, J.; Nazaroff, W. W.; Wilson, K. R.; Goldstein, A. H. Heterogeneous Ozonolysis of Squalene: Gas-Phase Products Depend on Water Vapor Concentration. Environmental Science \& Technology. 2019, 53, 14441-14448. 
430

431

432

433

434

435

436

437

438

439

440

441

442

443

444

445

446

447

448

449

450
25. Heine, N.; Houle, F. A.; Wilson, K. R. Connecting the Elementary Reaction Pathways of Criegee Intermediates to the Chemical Erosion of Squalene Interfaces during Ozonolysis. Environmental Science \& Technology. 2017, 51, 13740-13748.

26. Wang, C.; Collins, D. B.; Arata, C.; Goldstein, A. H.; Mattila, J. M.; Farmer, D. K.; Ampollini, L.; DeCarlo, P. F.; Novoselac, A.; Vance, M. E.; Nazaroff, W. W.; Abbatt, J. P. D. Surface reservoirs dominate dynamic gas-surface partitioning of many indoor air constituents. Science Advances. 2020, 6, eaay8973.

27. Nazaroff, W. W.; Weschler, C. J.; Corsi, R. L. Indoor air chemistry and physics. Atmospheric Environment. 2003, 37, 5451-5453.

28. Chen, C.; Zhao, B. Review of relationship between indoor and outdoor particles: I/O ratio, infiltration factor and penetration factor. Atmospheric Environment. 2011, 45, 275-288.

29. El Orch, Z.; Stephens, B.; Waring, M. S. Predictions and determinants of size-resolved particle infiltration factors in single-family homes in the U.S. Building and Environment. 2014, 74, 106-118.

30. Xiang, J.; Weschler, C. J.; Zhang, J.; Zhang, L.; Sun, Z.; Duan, X.; Zhang, Y. Ozone in urban China: Impact on mortalities and approaches for establishing indoor guideline concentrations. Indoor Air. 2019, 29, 604-615.

31. Hodas, N.; Meng, Q.; Lunden, M. M.; Rich, D. Q.; Özkaynak, H.; Baxter, L. K.; Zhang, Q.; Turpin, B. J. Variability in the fraction of ambient fine particulate matter found indoors and observed heterogeneity in health effect estimates. Journal of Exposure Science and Environmental Epidemiology. 2012, 22, 448-454. 
32. Chen, C.; Zhao, B.; Weschler, C. J. Assessing the Influence of Indoor Exposure to "Outdoor Ozone" on the Relationship between Ozone and Short-term Mortality in U.S. Communities. Environmental Health Perspectives. 2012, 120, 235-240.

33. Brauer, M.; Freedman, G.; Frostad, J.; van Donkelaar, A.; Martin, R. V.; Dentener, F.; van Dingenen, R.; Estep, K.; Amini, H.; Apte, J. S.; Balakrishnan, K.; Barregard, L.; Broday, D.; Feigin, V.; Ghosh, S.; Hopke, P. K.; Knibbs, L. D.; Kokubo, Y.; Liu, Y.; Ma, S.; Morawska, L.; Sangrador, J. L. T.; Shaddick G.; Anderson, H. R.; Vos, T.; Forouzanfar, M. H.; Burnett, R. T.; Cohen, A. Ambient Air Pollution Exposure Estimation for the Global Burden of Disease 2013. Environmental Science \& Technology. 2016, 50, 79-88.

34. Burnett, R. T.; Pope, C. A. III; Ezzati, M.; Olives, C.; Lim, S. S.; Mehta, S.; Shin, H. H.; Singh, G.; Hubbell, B.; Brauer, M.; Anderson, H. R.; Smith, K. R.; Balmes, J. R.; Bruce, N. G.; Kan, H.; Laden, F.; Prüss-Ustün, A.; Turner, M. C.; Gapstur, S. M.; Diver, W. R.; Cohen, A. An Integrated Risk Function for Estimating the Global Burden of Disease Attributable to Ambient Fine Particulate Matter Exposure. Environmental Health Perspectives. 2014, 122, $397-403$.

35. Apte, J. S.; Marshall, J. D.; Cohen, A. J.; Brauer, M. Addressing Global Mortality from Ambient PM2.5. Environmental Science \& Technology. 2015, 49, 8057-8066.

36. Ji, W.; Zhao, B. Estimating Mortality Derived from Indoor Exposure to Particles of Outdoor Origin. PLoS One. 2015, 10, e0124238.

37. Azimi, P.; Stephens, B. A framework for estimating the US mortality burden of fine particulate matter exposure attributable to indoor and outdoor microenvironments. Journal of Exposure Science and Environmental Epidemiology. 2020, 30, 271-284. 
473 38. Wallace, L. A.; Pellizzari, E. D.; Hartwell, T. D.; Sparacino, C.; Whitmore, R.; Sheldon, L.;

474 Zelon, H.; Perritt, R. The TEAM Study: Personal Exposures to Toxic Substances in Air,

475 Drinking Water, and Breath of 400 Residents of New Jersey, North Carolina, and North

476 Dakota. Environmental Research. 1987, 43, 290-307.

477 39. Weisel, C. P.; Zhang, J.; Turpin, B. J.; Morandi, M. T.; Colome, S.; Stock, T. H.; Spektor, D.

$478 \quad$ M.; Korn, L.; Winer, A.; Alimokhtari, S.; Kwon, J.; Mohan, K.; Harrington, R.; Giovanetti,

479 R.; Cui, W.; Afshar, M.; Maberti, S.; Shendell, D. Relationship of Indoor, Outdoor and

480 Personal Air (RIOPA) study: study design, methods and quality assurance/control results.

481 Journal of Exposure Analysis and Environmental Epidemiology. 2005, 15, 123-137.

482 40. Logue, J. M.; McKone, T. E.; Sherman, M. H.; Singer, B. C. Hazard assessment of chemical

483 air contaminants measured in residences. Indoor Air. 2011, 21, 92-109.

484 41. Liu, Y.; Misztal, P. K.; Xiong, J.; Tian, Y.; Arata, C.; Weber, R. J.; Nazaroff, W. W.;

485 Goldstein, A. H. Characterizing sources and emissions of volatile organic compounds in a

486 northern California residence using space- and time-resolved measurements. Indoor Air.

$487 \quad 2019,29,630-644$.

488 42. Levin, H. Building materials and indoor air quality. Occupational Medicine (Philadelphia,

$489 \quad P A)$. 1989, 4, 667-693.

490 43. Hodgson, A. T.; Wooley, J. D.; Daisey, J. M. Emissions of Volatile Organic Compounds

491 from New Carpets Measured in a Large-Scale Environmental Chamber. Journal of the Air \&

492 Waste Management Association. 1993, 43, 316-324.

493 44. Hodgson, A. T.; Beal, D.; McIlvaine, J. E. R. Sources of formaldehyde, other aldehydes and

494 terpenes in a new manufactured house. Indoor Air. 2002, 12, 235-242. 
45. Hites, R. A. Polybrominated Diphenyl Ethers in the Environment and in People: A MetaAnalysis of Concentrations. Environmental Science \& Technology. 2004, 38, 945-956.

46. Lamorena, R. B.; Jung, S.-G.; Bae, G.-N.; Lee, W. The formation of ultra-fine particles

498

499 during ozone-initiated oxidations with terpenes emitted from natural paint. Journal of

500

47. Corsi, R. L.; Lin, C.-C. Emissions of 2,2,4-Trimethyl-1,3-Pentanediol Monoisobutyrate

501 (TMPD-MIB) from Latex Paint: A Critical Review. Critical Reviews in Environmental

502 Science and Technology. 2009, 39, 1052-1080.

503

48. Nazaroff, W. W.; Weschler, C. J. Cleaning products and air fresheners: exposure to primary

504 and secondary air pollutants. Atmospheric Environment. 2004, 38, 2841-2865.

505

49. McDonald, B. C.; de Gouw, J. A.; Gilman, J. B.; Jathar, S. H. Akherati, A.; Cappa, C. D.;

506

507

508

509

510

511

512 Jimenez, J. L.; Lee-Taylor, J.; Hayes, P. L.; McKeen, S. A.; Cui, Y. Y.; Kim, S.-W.; Gentner,

7

$$
\text { D. R.; Isaacman-VanWertz, G.; Goldstein, A. H.; Harley, R. A.; Frost, G. J.; Roberts, J. M.; }
$$

Ryerson, T. B.; Trainer, M. Volatile chemical products emerging as largest petrochemical

source of urban organic emissions. Science. 2018, 359, 760-764.

50. Li, M.; Weschler, C. J.; Bekö, G.; Wargocki, P.; Lucic, D.; Williams, J. Human Ammonia

Emission Rates under Various Indoor Environmental Conditions. Environmental Science \&

Technology. 2020, 54, 5419-5428.

513 51. Mochalski, P.; Unterkofler, K.; Teschl, G.; Amann, A. Potential of volatile organic

514 compounds as markers of entrapped humans for use in urban search-and-rescue operations.

$515 \quad$ Trends in Analytical Chemistry. 2015, 68, 88-106.

516 52. Weschler, C. J. Roles of the human occupant in indoor chemistry. Indoor Air. 2016, 26, 6$517 \quad 24$. 
518 53. He, J.; Zou, Z.; Yang, X. Measuring whole-body volatile organic compound emission by

519 humans: A pilot study using an air-tight environmental chamber. Building and Environment.

$520 \quad 2019,153,101-109$.

521 54. de Lacey Costello, B.; Amann, A.; Al-Kateb, H.; Flynn, C.; Filipiak, W.; Khalid, T.;

522 Osborne, D.; Ratcliff, N. M. A review of the volatiles from the healthy human body. Journal

$523 \quad$ of Breath Research. 2014, 8, 014001.

524 55. Wisthaler, A.; Weschler, C. J. Reactions of ozone with human skin lipids: Sources of

525 carbonyls, dicarbonyls, and hydroxycarbonyls in indoor air. Proceedings of the National

526 Academy of Sciences of the U. S. A. 2010, 107, 6568-6575.

527 56. Anderson, S. E.; Franko, J.; Jackson, L. G.; Wells, J. R.; Ham, J. E.; Meade, B. J. Irritancy

528 and Allergic Responses Induced by Exposure to the Indoor Air Chemical 4-Oxopentanal.

$529 \quad$ Toxicological Sciences. 2012, 127, 371-381.

530 57. Guo, C.; Gao, Z.; Shen, J. Emission rates of indoor ozone emission devices: A literature $531 \quad$ review. Building and Environment. 2019, 158, 302-318.

532 58. Bhangar, S.; Mullen, N. A.; Hering, S. V.; Kreisberg N. M.; Nazaroff W. W. Ultrafine

533 particle concentrations and exposures in seven residences in northern California. Indoor Air.

$534 \quad 2011,21,132-144$.

535 59. Wallace, L. Indoor Particles: A Review. Journal of the Air \& Waste Management

$536 \quad$ Association. 1996, 46, 98-126.

537 60. Özkaynak, H.; Xue, J.; Spengler, J.; Wallace, L.; Pellizzari, E.; Jenkins, P. Personal Exposure

538 to Airborne Particles and Metals: Results from the Particle TEAM Study in Riverside,

539 California. Journal of Exposure Analysis and Environmental Epidemiology. 1996, 6, 57-78. 
540

541

542

543

544

545

546

547

548

549

550

551

552

553

554

555

556

557

558

559

560

561

61. Morawska, L.; Afshari, A.; Bae, G. N.; Buonanno, G.; Chao, C. Y. H.; Hänninen, O.;

Hofmann, W.; Isaxon, C.; Jayaratne, E. R.; Pasanen, P.; Salthammer, T.; Waring, M.;

Wierzbicka, A. Indoor aerosols: from personal exposure to risk assessment. Indoor Air. 2013, $23,462-487$.

62. Semple, S.; Creely, K. S.; Naji, A.; Miller, B. G.; Ayres, J. G. Secondhand smoke levels in Scottish pubs: the effect of smoke-free legislation. Tobacco Control. 2007, 16, 127-132.

63. Abdullahi, K. L.; Delgado-Saborit, J. M.; Harrison, R. M. Emissions and indoor concentrations of particulate matter and its specific chemical components from cooking: A review. Atmospheric Environment. 2013, 71, 260-294.

64. Bekö, G.; Weschler, C. J.; Wierzbicka, A.; Karottki, D. G.; Toftum, J.; Loft, S.; Clausen, G. Ultrafine Particles: Exposure and Source Apportionment in 56 Danish Homes. Environmental Science \& Technology. 2013, 47, 10240-10248.

65. Qian, J.; Peccia, J.; Ferro, A. R. Walking-induced particle resuspension in indoor environments. Atmospheric Environment. 2014, 89, 464-481.

66. Licina, D.; Tian, Y.; Nazaroff, W. W. Emission rates and the personal cloud effect associated with particle release from the perihuman environment. Indoor Air. 2017, 27, 791-802.

67. Deming, B. L.; Ziemann, P. J. Quantification of alkenes on indoor surfaces and implications for chemical sources and sinks. Indoor Air. 2020, 30, 914-924.

68. Weschler, C. J.; Carslaw, N. Indoor Chemistry. Environmental Science \& Technology. 2018, $52,2419-2428$.

69. Abbatt, J. P. D.; Wang, C. The atmospheric chemistry of indoor environments. Environmental Science: Processes \& Impacts. 2020, 22, 25-48. 
562 70. Arata, C.; Zarzana, K. J.; Misztal, P. K.; Liu, Y.; Brown, S. S.; Nazaroff, W. W.; Goldstein, 563 A. H. Measurement of $\mathrm{NO}_{3}$ and $\mathrm{N}_{2} \mathrm{O}_{5}$ in a Residential Kitchen. Environmental Science \& 564 Technology Letters. 2018, 5, 595-599.

565 71. Waring, M. S.; Wells, J. R. Volatile organic compound conversion by ozone, hydroxyl 566 radicals, and nitrate radicals in residential indoor air: Magnitudes and impacts of oxidant $567 \quad$ sources. Atmospheric Environment. 2015, 106, 382-391.

568 72. Seelye, K. Q. Kirk Smith, Towering Figure in Environmental Science, Dies at 73. New York 569 Times. 2020, June 24.

570 73. Logue, J. M.; Price, P. N.; Sherman, M. H.; Singer, B. C. A Method to Estimate the Chronic 571 Health Impact of Air Pollutants in U.S. Residences. Environmental Health Perspectives.

$572 \quad 2012,120,216-222$.

573 74. Tuomisto, J. T.; Wilson, A.; Evans, J. S.; Tainio, M. Uncertainty in mortality response to 574 airborne fine particulate matter: Combining European air pollution experts. Reliability $575 \quad$ Engineering and System Safety. 2008, 93, 732-744.

576 75. Salthammer, T.; Mentese, S.; Marutzky, R. Formaldehyde in the Indoor Environment.

$577 \quad$ Chemical Reviews. 2010, 110, 2536-2572.

578 76. Loh, M. M.; Levy, J. I.; Spengler, J. D.; Houseman, E. A.; Bennett, D. H. Ranking Cancer 579 Risks of Organic Hazardous Air Pollutants in the United States. Environmental Health $580 \quad$ Perspectives. 2007, 115, 1160-1168.

581 77. Sleiman, M.; Gundel, L. A.; Pankow, J. F.; Jacob, P. III; Singer, B. C.; Destaillats, H. 582 Formation of carcinogens indoors by surface-mediated reactions of nicotine with nitrous 583 acid, leading to potential thirdhand smoke hazards. Proceedings of the National Academy of $584 \quad$ Sciences of the U.S.A. 2010, 107, 6576-6581. 
585 78. Colborn, T.; vom Saal, F. S.; Soto, A. M. Developmental Effects of Endocrine-Disrupting 586 Chemicals in Wildlife and Humans. Environmental Health Perspectives. 1993, 101, 378$587 \quad 384$.

588 79. Rudel, R. A.; Fenton, S. E.; Ackerman, J. M.; Euling, S. Y.; Makris, S. L. Environmental 589 Exposures and Mammary Gland Development: State of the Science, Public Health 590 Implications, and Research Recommendations. Environmental Health Perspectives. 2011, $591 \quad 119,1053-1061$.

592 80. Weschler, C. J. Changes in indoor pollutants since the 1950s. Atmospheric Environment. $593 \quad 2009,43,156-172$.

594 81. Wang, Z.; Walker, G. W.; Muir, D. C. G.; Nagatani-Yoshida, K. Toward a Global 595 Understanding of Chemical Pollution: A First Comprehensive Analysis of National and 596 Regional Chemical Inventories. Environmental Science \& Technology. 2020, 54, 2575-2584.

597 82. Rudel, R. A.; Perovich, L. J. Endocrine disrupting chemicals in indoor and outdoor air. $598 \quad$ Atmospheric Environment. 2009, 43, 170-181.

599 83. Bornehag, C. G.; Nanberg E. Phthalate exposure and asthma in children. International $600 \quad$ Journal of Andrology. 2010, 33, 333-345.

601 84. Weschler, C. J.; Nazaroff, W. W. Dermal Uptake of Organic Vapors Commonly Found in 602 Indoor Air. Environmental Science \& Technology. 2014, 48, 1230-1237.

603 85. Salthammer, T.; Zhang, Y.; Mo, J.; Koch, H. M.; Weschler, C. J., Assessing Human 604 Exposure to Organic Pollutants in the Indoor Environment. Angewandte Chemie$605 \quad$ International Edition. 2018, 57, 12228-12263.

606 86. Birnbaum, L. S. State of the Science of Endocrine Disruptors. Environmental Health $607 \quad$ Perspectives. 2013, 121, a107-a107. 
87. Schug, T. T.; Johnson, A. F.; Birnbaum, L. S.; Colborn, T.; Guillette Jr, L. J.; Crews, D. P.; Collins, T.; Soto, A. M.; vom Saal, F. S.; McLachlan, J. A.; Sonnenschein, C.; Heindel, J. J. Endocrine Disruptors: Past Lessons and Future Directions. Molecular Endocrinology. 2016, $30,833-847$.

88. Egusquiza, R. J.; Blumberg, B. Environmental Obesogens and Their Impact on Susceptibility to Obesity: New Mechanisms and Chemicals. Endocrinology. 2020, 161, 1-14.

89. United Nations, Department of Economic and Social Affairs, Population Division. World Urbanization Prospects: The 2018 Revision. Report ST/ESA/SER.A/420. New York: United Nations. 2019. https://population.un.org/wup/Publications/Files/WUP2018-Report.pdf

90. Zhang, Y.; Mo, J.; Weschler, C. J. Reducing Health Risks from Indoor Exposures in Rapidly Developing Urban China. Environmental Health Perspectives. 2013, 121, 751-755.

91. Lelieveld, J.; Evans, J. S.; Fnais, M.; Giannadaki, D.; Pozzer, A. The contribution of outdoor air pollution sources to premature mortality on a global scale. Nature. 2015, 525, 367-371.

92. Zhong, L.; Lee, C.-S.; Haghighat, F. Indoor ozone and climate change. Sustainable Cities and Society. 2017, 28, 466-472.

93. McCarthy, M. P.; Best, M. J.; Betts, R. A. Climate change in cities due to global warming and urban effects. Geophysical Research Letters. 2010, 37, L09705.

94. Lelieveld, J.; Proestos, Y.; Hadjinicolaou, P.; Tanarhte, M.; Tyrlis, E.; Zittis, G. Strongly increasing heat extremes in the Middle East and North Africa (MENA) in the 21st century. Climatic Change. 2016, 137, 245-260.

95. Landrigan P.J.; Fuller, R.; Acosta, N. J. R.; Adeyi, O.; Arnold, R.; Basu, N.; Bibi Baldé, A.; Bertollini, R.; Bose-O’Reilly, S.; Boufford, J. I.; Breysse, P. N.; Chiles, T.; Mahidol, C.; Coll-Seck, A. M.; Cropper, M. L.; Fobil, J.; Fuster, V.; Greenstone, M.; Haines, A.; 
647 648

649 650 651 652

Hanrahan, D.; Hunter, D.; Khare, M.; Krupnick, A.; Lanphear, B.; Lohani, B.; Martin, K.; Mathiasen, K. V.; McTeer, M. A.; Murray, C. J. L., Ndahimananjara, J. D.; Perera, F.;

Potočnik, J.; Preker, A. S.; Ramesh, J.; Rockström, J.; Salinas, C.; Samson, L. D.; Sandilya, K.; Sly, P. D.; Smith, K. R.; Steiner, A.; Stewart, R. B.; Suk, W. A.; van Schayck, O. C. P.; Yadama, G. N.; Yumkella, K.; Zhong, M. The Lancet Commission on pollution and health. Lancet. 2018, 391, 462-512.

96. Hardin, G.; The Tragedy of the Commons. Science. 1968, 162, 1243-1248.

97. Shair, F. H. Relating Indoor Pollutant Concentrations of Ozone and Sulfur Dioxide to Those Outside: Economic Reduction of Indoor Ozone Through Selective Filtration of the Make-up Air. ASHRAE Transactions. 1981, 87 (Part I), 116-139.

98. Ben-David, T.; Wang, S.; Rackes, A.; Waring, M. S. Measuring the efficacy of HVAC particle filtration over a range of ventilation rates in an office building. Building and Environment. 2018, 144, 648-656.

99. Bekö, G.; Clausen, G.; Weschler, C. J. Is the use of particle air filtration justified? Costs and benefits of filtration with regard to health effects, building cleaning and occupant productivity. Building and Environment. 2008, 43, 1647-1657.

100. Zhao, D.; Azimi, P.; Stephens, B. Evaluating the Long-Term Health and Economic Impacts of Central Residential Air Filtration for Reducing Premature Mortality Associated with Indoor Fine Particulate Matter $\left(\mathrm{PM}_{2.5}\right)$ of Outdoor Origin. International Journal of Environmental Research and Public Health. 2015, 12, 8448-8479.

101. Fisk, W. J.; Chan, W. R. Effectiveness and cost of reducing particle-related mortality with particle filtration. Indoor Air. 2017, 27, 909-920. 
653 102. Day D. B.; Xiang, J.; Mo, J.; Li, F.; Chung, M.; Gong, J.; Weschler, C. J.; Ohman-

654 Strickland, P. A.; Sundell, J.; Weng, W.; Zhang, Y.; Zhang, J. Association of Ozone

655 Exposure With Cardiorespiratory Pathophysiologic Mechanisms in Healthy Adults. JAMA

$656 \quad$ Internal Medicine. 2017, 177, 1344-1353.

657 103. Cui, X.; Li, F.; Xiang J.; Fang, L.; Chung, M. K.; Day, D. B.; Mo, J.; Weschler, C. J.;

658 Gong, J.; He, L.; Zhu, D.; Lu, C.; Han, H.; Zhang, Y.; Zhang J. Cardiopulmonary effects of

659 overnight indoor air filtration in health non-smoking adults: A double-blind randomized

$660 \quad$ crossover study. Environment International. 2018, 114, 27-36.

661 104. United States Environmental Protection Agency. Residential Air Cleaners: A Technical

662 Summary, $3^{\text {rd }}$ Edition. Portable Air Cleaners, Furnace and HVAC Filters. Report EPA 402-F-

663 09-002. EPA Indoor Environments Division. July 2018.

664 105. Dockery, D. W.; Spengler, J. D. Indoor-Outdoor Relationships of Respirable Sulfates and

665 Particles. Atmospheric Environment. 1981, 15, 335-343.

666

667

668

669

670

671

672

673

674

675 


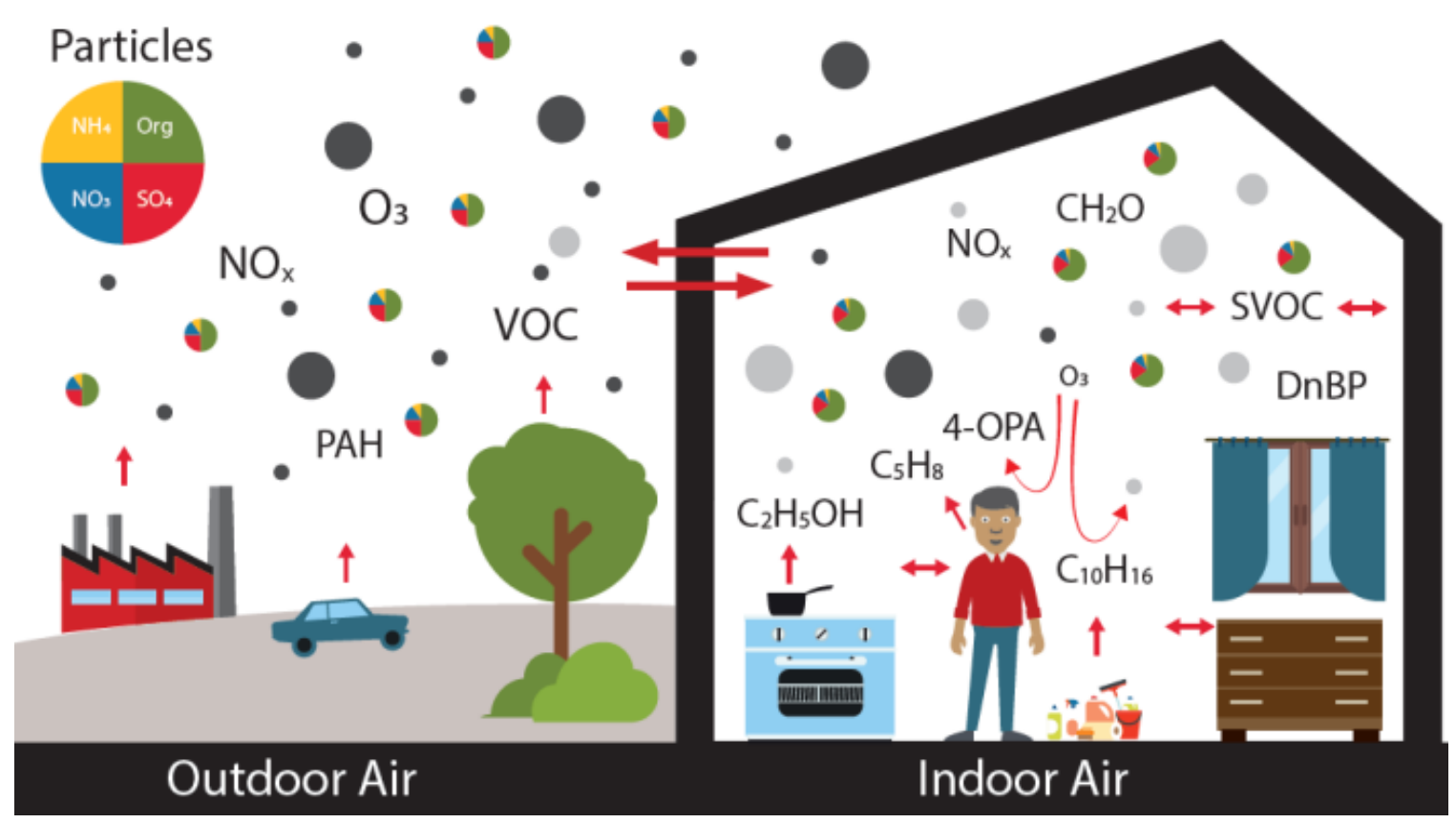

678

679 Figure 1. Schematic illustration of selected air pollutant transformations that occur between outdoor and indoor air. Pie charts indicate fine-mode particle composition (legend top left,

681 following color scheme of Zhang et al. ${ }^{7}$ ). Note outdoor versus indoor differences in particle size distributions, particle composition, ozone, and sources. Solid black circles represent ultrafineand coarse-mode particles of outdoor origin; buildings attenuate their outdoor-to-indoor transport. Solid light gray circles represent particles of indoor origin, some of which are transported outdoors. Ozone tends to have a much larger concentration outdoors than indoors

686 (suggested by font size), reflecting reactions on indoor surfaces and in air that generate gaseous 687 and condensed-phase products. Multiple indoor sources of organic compounds result in indoor 688 concentrations much larger than those outdoors. Indoor organics partition among the air, airborne 689 particles, room and human surfaces. 